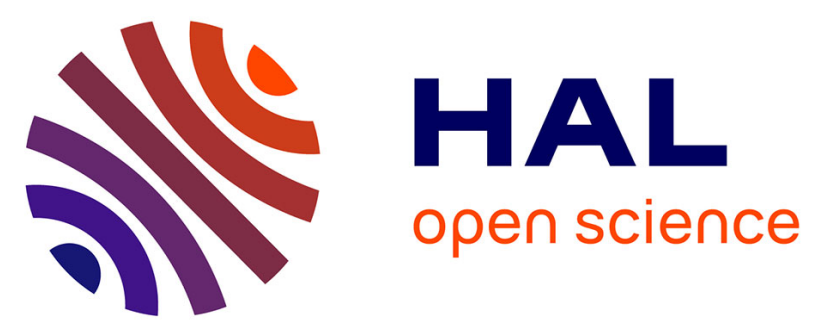

\title{
Sensitive determination of glyoxal, methylglyoxal and hydroxyacetaldehyde in environmental water samples by using dansylacetamidooxyamine derivatization and liquid chromatography/fluorescence
}

S. Houdier, Manuel Barret, Florent Dominé, Tiffany Charbouillot, Laurent

Deguillaume, Didier Voisin

\section{To cite this version:}

S. Houdier, Manuel Barret, Florent Dominé, Tiffany Charbouillot, Laurent Deguillaume, et al.. Sensitive determination of glyoxal, methylglyoxal and hydroxyacetaldehyde in environmental water samples by using dansylacetamidooxyamine derivatization and liquid chromatography/fluorescence. Analytica Chimica Acta, 2011, 704 (1-2), pp.162-173. 10.1016/j.aca.2011.08.002 . hal-01998763

\author{
HAL Id: hal-01998763 \\ https://hal.uca.fr/hal-01998763
}

Submitted on 15 Feb 2019

HAL is a multi-disciplinary open access archive for the deposit and dissemination of scientific research documents, whether they are published or not. The documents may come from teaching and research institutions in France or abroad, or from public or private research centers.
L'archive ouverte pluridisciplinaire HAL, est destinée au dépôt et à la diffusion de documents scientifiques de niveau recherche, publiés ou non, émanant des établissements d'enseignement et de recherche français ou étrangers, des laboratoires publics ou privés. 


\title{
Sensitive determination of glyoxal, methylglyoxal and hydroxyacetaldehyde in environmental water samples by using dansylacetamidooxyamine derivatization and liquid chromatography/fluorescence
}

\author{
Stéphan Houdier ${ }^{\mathrm{a}, *}$, Manuel Barret ${ }^{\mathrm{a}}$, Florent Dominé ${ }^{\mathrm{a}}$, Tiffany Charbouillot ${ }^{\mathrm{b}}$, \\ Laurent Deguillaume ${ }^{\mathrm{c}}$, Didier Voisin ${ }^{\mathrm{a}}$ \\ a Laboratoire de Glaciologie et Géophysique de l'Environnement, UMR 5183, Université Joseph Fourier-Grenoble 1/CNRS, Grenoble, F-38041, France \\ ${ }^{\mathrm{b}}$ Laboratoire de Photochimie Moléculaire et Macromoléculaire, UMR 6505, Université Blaise Pascal/CNRS, Clermont-Ferrand, F-63000, France \\ c Laboratoire de Météorologie Physique, UMR 6016, Université Blaise Pascal/CNRS, Clermont-Ferrand, F-63000, France
}

\section{A R T I C L E I N F O}

\section{Article history:}

Received 2 March 2011

Received in revised form 28 July 2011

Accepted 1 August 2011

Available online 9 August 2011

\section{Keywords:}

HPLC

Fluorescence

Dicarbonyl compounds

Hydroxyaldehydes

Water samples

Environment

\begin{abstract}
A B S T R A C T
In this study we improved the dansylacetamidooxyamine (DNSAOA)-LC-fluorescence method for the determination of aqueous-phase glyoxal (GL), methylglyoxal (MG) and hydroxyacetaldehyde (HA). As derivatization of dicarbonyls can potentially lead to complex mixtures, a thorough study of the reaction patterns of GL and MG with DNSAOA was carried out. Derivatization of GL and MG was shown to follow the kinetics of successive reactions, yielding predominantly doubly derivatized compounds. We verified that the bis-DNSAOA structure of these adducts exerted only minor influence on their fluorescence properties. Contrary to observations made with formaldehyde, derivatization of GL, MG and, to a lesser extent of HA was shown to be faster in acidic $\left(\mathrm{H}_{2} \mathrm{SO}_{4}\right)$ medium with a maximum of efficiency for acid concentrations of ca. $2.5 \mathrm{mM}$. Concomitant separation of GL, MG, HA and of single carbonyls was achieved within $20 \mathrm{~min}$ by using $\mathrm{C}_{18}$ chromatography and a gradient of $\mathrm{CH}_{3} \mathrm{CN}$ in water. Detection limits of $0.27,0.17$ and $0.12 \mathrm{nM}$ were determined for GL, MG and HA, respectively. Consequently, low sample volumes are sufficient and, unlike numerous published methods, neither preconcentration nor large injection volumes are necessary to monitor trace-level samples. The method shows relative measurement uncertainties better than $\pm 15 \%$ at the $95 \%$ level of confidence and good dynamic ranges $\left(R^{2}>0.99\right)$ from 0.01 to $1.5 \mu \mathrm{M}$ for all carbonyls. GL, MG and HA were identified for the first time in polar snow samples, but also in saline frost flowers for which unexpected levels of $0.1-0.6 \mu \mathrm{M}$ were measured. Concentrations in the $0.02-2.3 \mu \mathrm{M}$ range were also measured in cloud water. In most samples, a predominance of HA over GL and MG was observed.
\end{abstract}

(C) 2011 Elsevier B.V. All rights reserved.

\section{Introduction}

In addition to formaldehyde (HCHO, FA), the main aldehyde present in the atmosphere, $\alpha$-dicarbonyls $(\alpha \mathrm{DCs})$ glyoxal (CHOCHO, GL) and methylglyoxal $\left(\mathrm{CH}_{3} \mathrm{COCHO}, \mathrm{MG}\right)$, but also hydroxyacetaldehyde $\left(\mathrm{CHOCH}_{2} \mathrm{OH}, \mathrm{HA}\right)$ have attracted particular attention over the past few years because of their potential role in secondary organic aerosol (SOA) formation [1-4] (see Table 1 for a list of the acronyms used throughout the paper). These compounds, grouped under the term " $\alpha$-oxygenated carbonyls" ( $\alpha$ OCs), mostly originate from the oxidation of biogenic hydrocarbons such as isoprene [1,3,5]. Oxidation of toluene [1] or acetylene [3], which are typical anthropogenic hydrocarbons, is also thought to yield GL and MG. GL, MG and HA exhibit high Henry's law coefficients [6,7] and

\footnotetext{
* Corresponding author. Tel.: +33 476824211; fax: +33 476824201 .

E-mail address: houdier@lgge.obs.ujf-grenoble.fr (S. Houdier).
}

can be largely scavenged from the atmosphere by cloud, fog, dew water, rain or snow. In stagnant cloud droplets they can be further oxidized to form low volatility dicarboxylic acids or be involved in the formation of oligomers $[2,4,8]$ which upon droplet evaporation, may condense contributing to SOA. Like many other substances, carbonyls can also be incorporated in snow [9]. As already shown for FA $[10,11]$, acetaldehyde $\left(\mathrm{CH}_{3} \mathrm{CHO}, \mathrm{AA}\right)[12-14]$ or acetone $\left(\mathrm{CH}_{3} \mathrm{COCH}_{3}, \mathrm{AC}\right)[13,15]$, the behavior of carbonyls in snow is rather complex, involving physical exchanges with the atmosphere or photochemical production within the snowpack from organic precursors. Carbonyls can also absorb photons and generate radicals which can in turn react with other substances, including organic compounds [16]. These processes may strongly impact the composition of the overlying air, particularly in polar regions where the mixing layer is thin $[9,16]$. The contribution of $\alpha O C s$ to these processes remains unknown and constitutes our main motivation to develop a method capable of measuring these species in the presumably low-concentrated polar snow or ice samples. In cloud 
Table 1

List of acronyms.

\begin{tabular}{|c|c|c|c|}
\hline Acronym & Meaning & Acronym & Meaning \\
\hline AA & Acetaldehyde & HA & Hydroxyacetaldehyde \\
\hline$A C$ & Acetone & LC & Liquid chromatography \\
\hline$\alpha \mathrm{DCs}$ & Alpha-dicarbonyl compounds & LOD & Limit of detection \\
\hline$\alpha \mathrm{OCs}$ & Alpha-oxygenated carbonyl compounds & LOQ & Limit of quantification \\
\hline DNPH & Dinitrophenylhydrazine & MDQ & Minimum detectable quantity \\
\hline DNS & Dansyl & MG & Methylglyoxal \\
\hline DNSAOA & Dansylacetamidooxyamine & OASIS & Ocean Atmosphere Sea-Ice Snowpack \\
\hline FA & Formaldehyde & PFO & Pseudo-first-order \\
\hline FF & Frost flowers & SAE & Sum of absolute errors \\
\hline GL & Glyoxal & SOA & Secondary organic aerosols \\
\hline
\end{tabular}

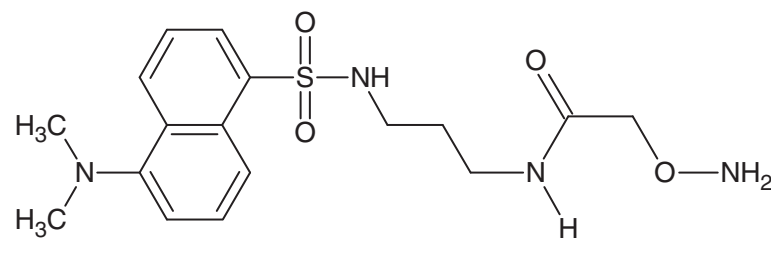

Scheme 1. Chemical structure of DNSAOA (1).

water or rain, higher concentration levels are expected and our method would in theory also be suitable for the assay of $\alpha \mathrm{OCs}$ in these matrices.

Carbonyl compounds are generally determined by indirect methods involving a preliminary derivatization step. Various derivatizing reagents have been reported for the measurement of carbonyls in the environment [17]. Among them, 2,4-dinitrophenylhydrazine (DNPH) has undoubtedly been the most extensively used. The DNPH method was used notably for the determination of both single carbonyls and $\alpha \mathrm{DCs}$ in the different types of environmental water samples we focus on [18-26]. Aromatic $o$-diamino compounds react selectively with $\alpha \mathrm{DCs}$, yielding highly fluorescent quinoxalines [27-30]. 2,3-diaminonaphtalene (DAN) belongs to this class of compounds and was used to determine GL and MG in tap water [29]. The selective measurement of both GL and MG in rain and snow was also achieved through their transformation into the corresponding dibutyl acetals by reaction with $\mathrm{BF}_{3} / n$-butanol [31-33]. It is noteworthy that measurements of HA in hydrometeors have rarely been reported. Matsunaga and Kawamura [34] and Matsunaga et al. [35] used obenzylhydroxylamine (BHA) to determine GL, MG and HA in snow and rain samples. To the best of our knowledge, only these studies carried out by Matsumoto et al. [24] and Igawa et al. [36] have reported on the concomitant measurement of single aldehydes, GL, MG and HA in rain, fog and dew water.

Houdier et al. [37,38] have proposed the use of 2aminooxy-N-[3-(5-dimethylamino-naphtalene-1-sulfonylamino)propyl]-acetamide (dansylacetamidooxyamine, DNSAOA, 1) (Scheme 1) as a sensitive probe for the detection of carbonyls in natural water samples. Reaction between 1 and carbonyls yields oxime ethers that are separated by reversed-phase LC, and detected by fluorescence spectroscopy. The method has been applied to the trace determination of C1-C4 linear aldehydes in cloud-water, ice, alpine snow [38], and more intensively in polar snow samples $[10,13,14,38,39]$. Low $\alpha$ OCs levels in polar samples, combined with the poor reactivity of GL and MG with the experimental conditions used, and the intricate LC separation of the HA derivative, explain why Houdier et al. did not measure $\alpha$ OCs.

This study shows that slight modifications of the original DNSAOA method render the determination of aqueous-phase GL, MG and HA concentrations possible. Given that GL and MG are dicarbonyls, theoretically either mono- (2a and 3a) or bis-DNSAOA (2b and $\mathbf{3 b}$ ) oximes can be obtained (Scheme 2), potentially leading to complex reaction mixtures. The first part of this work was thus dedicated to a thorough study of the characteristic features of the reactions of GL and MG with $\mathbf{1}$. Though straightforward, the isocratic elution mode used in this preliminary study was unable to achieve the separation of the HA adduct. Subsequently, gradient elution mode was used to study the reaction behavior of HA with 1 (leading to $\mathbf{5}$, Scheme 2 ), and to assess the analytical performances of the method. Because we are particularly interested in polar snow analysis, we strove to improve sensitivity. Finally, the method was applied to the analysis of the carbonyl content of different environmental matrices: cloud water, rain, alpine or polar snow, along with saline samples such as brine and frost flowers. This latter matrix consists in ice crystals that form on the surface of young sea-ice [40].

\section{Experimental}

\subsection{Materials and reagents}

Glyoxal (40\%,w/w) and methylglyoxal (40\%) were purchased from Sigma Chemical Co. (St Louis, MO). Hydroxyacetaldehyde dimer was obtained from Fluka (Buchs, Switzerland). Formaldehyde (37\%), acetone (ACS reagent), sulphuric acid (ACS reagents) were from Acros Organics (Geel, Belgium). Acetonitrile (LC Grade) was obtained from Fisher Scientific (Loughborough, UK). Ultrapure water was delivered by an Elga (High Wycombe Bucks, UK) Maxima HPLC system. Stock solutions ( $\mathrm{ca} .1 \mathrm{mM}$ ) of the carbonyls in ultrapure water were stored at $4{ }^{\circ} \mathrm{C}$. These solutions were further diluted to afford the ca. $10 \mu \mathrm{M}$ solutions used to prepare the standard reacting solutions. 1 was obtained from crystalline DNSAOA- $t$ butyloxycarbamate by acidic deprotection of the $t$-BOC protecting group [38]. Stock solutions of $\mathbf{1}$ in water (typically $0.5-2 \mathrm{mM}$ ) were stored at $-15^{\circ} \mathrm{C}$ and melted just before use.

\subsection{Sample collection and storage}

All snow and rain samples were collected in $60 \mathrm{~mL}$ borosilicated glass vials for EPA analysis (Kimble Glass Inc., Vineland, NJ) with PTFE/silicone-lined caps. Vials were preliminarily washed with ultrapure water and carefully rinsed immediately before sampling. For snow sampling, vials were left to cool to ambient temperature before being filled with snow by inserting them horizontally in the layer of interest. Depending on snow density, water equivalent volumes typically ranging from 5 to $20 \mathrm{~mL}$ were collected. Frost flowers and brine were collected at the sea-ice surface in a manner similar to snow samples. A glass funnel was used to collect our rain sample $(20 \mathrm{~mL})$ directly into a $60 \mathrm{~mL}$ glass vial. Cloud water samples were collected by a one stage cloud impactor made of stainless steel and aluminum [41] with a protection screen for the wind. With the air flow used $\left(86 \mathrm{~m}^{3} \mathrm{~h}^{-1}\right)$, the lower limit of the aerodynamic diameter of collected droplets was about $7 \mu \mathrm{m}$, which ensured $80 \%$ collection efficiency. The sampling time ranged 


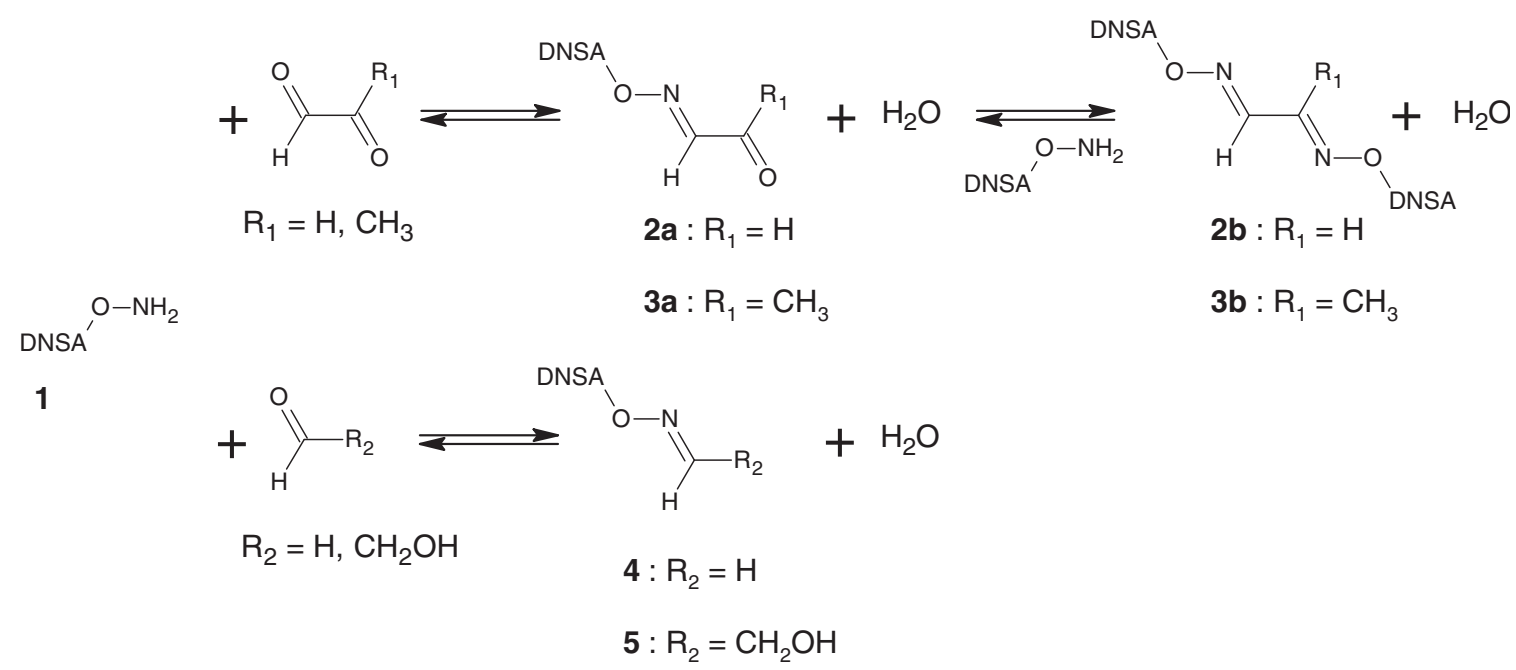

Scheme 2. Derivatization of GL, MG, HA and FA with 1. Only the s-anti, E, E isomers of $\mathbf{2 b}$ and $\mathbf{3 b}$ are represented.

from 60 to $180 \mathrm{~min}$, depending on the liquid water content of the cloud, and typically 30-60 mL of water was collected. Cloud water samples were placed in $100 \mathrm{~mL}$ borosilicated Duran ${ }^{\circledR}$ glass bottles (Schott, Mainz, Germany). After collection, samples were stored in the shade and placed in a freezer at $-15^{\circ} \mathrm{C}$ until analysis. Samples collected during the polar campaign were stored in a cold room at $-40^{\circ} \mathrm{C}$. Freezing is necessary to prevent sample contamination by atmospheric carbonyls. This is particularly true for low-level samples in which carbonyls are undersaturated respecting to the gas phase. Freezing and light protection also inhibit post-sampling contamination through photochemical reactions or microbiological degradation of the dissolved organic matter naturally present in environmental samples. We tested the efficiency of these precautions by analyzing snow samples fresh or after a $6 \mathrm{~h}$ to 7 days storage at $-15^{\circ} \mathrm{C}$ and obtained fresh/stored recoveries in the $\mathrm{ca}$. $90-110 \%$, coherent with the uncertainties determined in Section 3.7.2. Nevertheless, when feasible, samples were analyzed right after their collection. This was often the case during the polar campaign where the sampling sites and the laboratory were in vicinity.

\subsection{Preparation of samples and standard reacting solutions}

All derivatization reactions were performed in $1.8 \mathrm{~mL}$ clear glass Qsert vials caped with LectraBond PTFE/silicone septa (Waters, Milford, MA). Vials were preliminarily filled with $\mathrm{HNO}_{3}(10 \%, \mathrm{v} / \mathrm{v})$ and allowed to stand for at least $1 \mathrm{~h}$ before being rinsed with ultrapure water. Experiments carried out to evaluate the derivatization processes and the performances of the method were conducted with reacting solutions prepared according to the procedure described below for natural samples, simply by replacing the sample aliquot with ultrapure water. To a $1.5 \mathrm{~mL}$ aliquot of freshly melted sample were added typically 5-20 $\mu \mathrm{L}$ of the stock solution of $\mathbf{1}$ and, for catalyzed experiments, $2 \mu \mathrm{L}$ of $\mathrm{H}_{2} \mathrm{SO}_{4}(10 \%$, v/v) leading to reacting solutions ca. $2.5 \mathrm{mM}$ in $\mathrm{H}_{2} \mathrm{SO}_{4}$. Typically, the reaction mixture was allowed to stand for $36 \mathrm{~h}$ at room temperature in a shaded area before LC analysis. Cloud water, brine and frost flower samples were diluted (usually a ratio of 2-10) with ultrapure water to reach a final volume of $1.5 \mathrm{~mL}$. The standard addition method was used for calibration. Standard reacting mixtures were prepared with volumes of the natural sample and stock solution of $\mathbf{1}$ identical to those used for the sample preparation. Increasing volumes (typically 0-40 $\mu \mathrm{L}$ ) of a freshly prepared ca. $10 \mu \mathrm{M}$ solution containing all the carbonyls of interest were added to give the standard reacting mixtures.

\subsection{LC system and elution modes}

LC-fluorescence analyses were carried out by a system made up of a Waters (Waters, Milford, MA) 600E Multisolvent Delivery System, a Rheodyne (Rheodyne, Cotati, CA) 7725i injection valve mounted with a $5 \mu \mathrm{L}$ loop, and a Waters 474 fluorescence detector mounted with a $16 \mu \mathrm{L}$ flow cell. Excitation and emission wavelengths were set to 330 and $530 \mathrm{~nm}$, respectively. Emission slit bandwidth was set to $40 \mathrm{~nm}$ and RC filter mode with standard response was selected. The electronic gain was adjusted to 100 or 1000 depending on sensitivity requirements. Data acquisition and analysis were performed by using a Hercule2000 chromatography interface (JMBS Developments, France) and the Galaxie chromatography data software (Varian Inc., Palo Alto, CA). LC separations were carried out by using two different chromatographic conditions thereafter referred to as Isocratic Mode and Gradient Mode:

Isocratic mode: Column: Macherey-Nagel (Düren, Germany) Nucleodur $\mathrm{C}_{18}$ column ( $5 \mu \mathrm{m}$ particle size, $100 \AA$ pore size, $4 \mathrm{~mm} \times 250 \mathrm{~mm})$. Flow rate: $1.25 \mathrm{~mL} \mathrm{~min}^{-1}$. Eluent: $49 / 51(\mathrm{v} / \mathrm{v})$ $\mathrm{H}_{2} \mathrm{O} / \mathrm{CH}_{3} \mathrm{CN}$.

Gradient mode: Column: Dionex (Camberley, UK) Acclaim $120 \mathrm{C}_{18}$ column $(3 \mu \mathrm{m}, 120 \AA, 4.6 \mathrm{~mm} \times 150 \mathrm{~mm})$. Flow rate: $1 \mathrm{~mL} \mathrm{~min}^{-1}$. Gradient elution program: we used a concave gradient (curve 9 of the Waters 600E) which evolved from 68/32 to $43 / 57(\mathrm{v} / \mathrm{v})$ $\mathrm{H}_{2} \mathrm{O} / \mathrm{CH}_{3} \mathrm{CN}$ within $8 \mathrm{~min}$. LC continued on $43 / 57(\mathrm{v} / \mathrm{v})$ for a further $8 \mathrm{~min}$ before returning to initial conditions (i.e. 68/32, v/v) following a concave gradient (curve 7 ) within $3 \mathrm{~min}$.

Fluorescence excitation and emission spectra of compounds 2b, 3b and 4 were scanned with the Waters 474 detector and Isocratic elution mode. An aliquot $(5 \mu \mathrm{L})$ of a solution of each adduct $(3.3 \mu \mathrm{M})$ was injected in the present LC system and the flow was interrupted when the solute of interest was located in the flow cell. Emission and excitation spectra were recorded over the $265-520\left(\lambda_{\mathrm{em}}=530 \mathrm{~nm}\right)$ and $340-650 \mathrm{~nm}\left(\lambda_{\mathrm{ex}}=330 \mathrm{~nm}\right)$ ranges, respectively.

\subsection{Mass spectrometry}

Mass spectrometric identification of the GL and MG adducts was made by coupling an electrospray ionization ion trap mass spectrometer (LCQ Fleet, Thermo Fischer Scientific, Waltham, MA) with the LC-fluorescence system. Positive mode ionization was used, with a $5 \mathrm{kV}$ spray voltage. Sheath gas and auxiliary gas-flow rates 


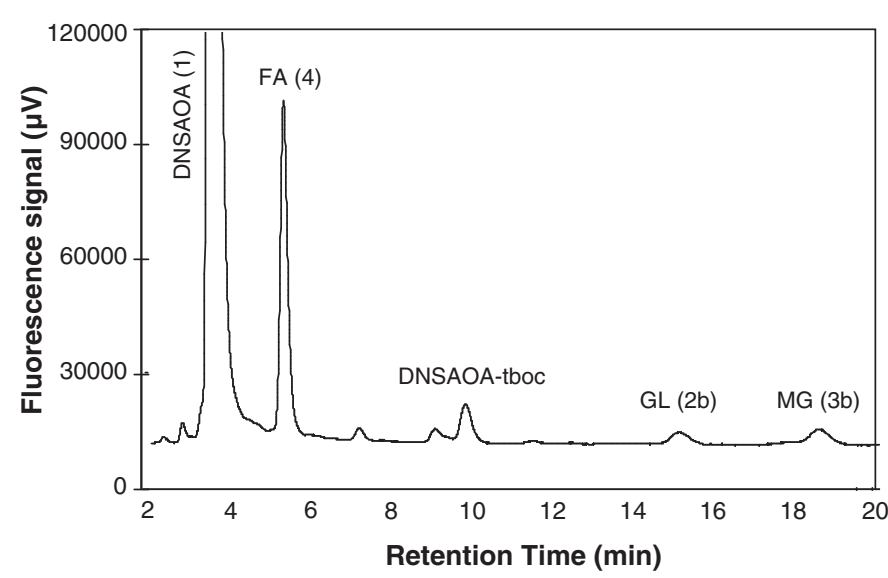

Fig. 1. Chromatogram of a mixture of $\mathbf{1}(5.0 \mu \mathrm{M})$ and of DNSAOA derivatives of FA (4), GL (2b) and MG (3b) (0.1 $\mu \mathrm{M}$ each). Reaction time was $36 \mathrm{~h}$. Peaks at $t_{\mathrm{r}}=7.2$ and $9.8 \mathrm{~min}$ are due to residual contamination by the DNSAOA adduct of AC and DNSAOA-t-Boc [38], respectively. LC conditions: Isocratic Mode.

were set to 8 and 5 arbitrary units, respectively. Transfer capillary temperature and voltage were set at $275^{\circ} \mathrm{C}$ and $29 \mathrm{~V}$, respectively. A tube lens voltage of $63 \mathrm{~V}$ was selected to minimize unwanted fragmentation and to keep clustering by the solvent to a minimum. Full-scan spectra were obtained in the 50-1000 amu range. Each full-scan spectrum was obtained by averaging the spectrum over the elution peak and subtracting the background spectrum measured immediately before and after the peak. The signal to noise ratio observed for the adducts peaks was of the order of 3000 .

\section{Results and discussion}

\subsection{LC identification and MS characterization of the DNSAOA adducts of GL and MG}

Chromatographic identification of the DNSAOA oxime ethers of GL and MG was achieved by preparing a solution of $\mathbf{1}$ and of the dicarbonyls in ultrapure water. FA was added to the solution to serve as a reference. Carbonyl concentrations were chosen to match those expected for moderately concentrated natural samples i.e. $0.15 \mu \mathrm{M}$. In accordance with the protocol described by Houdier et al. [38] for routine analysis of linear aldehydes, a 10fold molar excess of $\mathbf{1}$ vs total aldehydes was used and no catalyst was added. Fig. 1 shows a typical chromatogram of the mixture obtained after $36 \mathrm{~h}$ reaction. Isocratic chromatographic conditions used were close to those reported in [38] for the separation of the DNSAOA adducts of $\mathrm{C} 1-\mathrm{C} 4$ linear aldehydes. Under these conditions 1, DNSAOA-FA (4) and two peaks ( $t_{\mathrm{r}}=15.2$ and $\left.18.7 \mathrm{~min}\right)$, a priori attributable to the DNSAOA adducts of GL and MG, are clearly defined. Identification of the compounds eluting at 15.2 and $18.7 \mathrm{~min}$ as mono- (2a and $\mathbf{3 a}$ ) or bis-DNSAOA oximes (2b and 3b) was achieved by coupling the LC system to an electrospray ion trap mass spectrometer. The full scan spectrum of the compound eluting at $15.2 \mathrm{~min}$ (Fig. 2a) shows a base peak at $m / z 783$ corresponding to the molecular ion $[\mathrm{M}+\mathrm{H}]^{+}$of $\mathbf{2} \mathbf{b}$. The intense ion at $m / z$ 805 , which corresponds to the sodium adduct $[\mathrm{M}+\mathrm{Na}]^{+}$, helps to confirm the bis-DNSAOA structure. A similar ESI spectrum (Fig. 2b) was obtained for the peak eluting at $18.7 \mathrm{~min}$ where ions at $\mathrm{m} / \mathrm{z}$ 797 (base peak) and $m / z 819$ can be attributed to the $[\mathrm{M}+\mathrm{H}]^{+}$and $[\mathrm{M}+\mathrm{Na}]^{+}$ions of $\mathbf{3 b}$, respectively. It is worth mentioning that each spectrum shows a peak at $m / z[M+44]^{+}$whose structure remains unelucidated. These spectra do not reveal $\left[\mathrm{M}+(44)_{n}\right]^{+}$ion series and we excluded contamination by polyethylene glycol, a common contaminant encountered in LC/MS systems. Nevertheless, similar $[\mathrm{M}+44]^{+}$peaks were observed for compounds $\mathbf{1}$ and $\mathbf{4}$, leading us to suppose that $[\mathrm{M}+44]^{+}$ions at $m / z 827$ and 841 in Fig. $2 \mathrm{a}$ and $\mathrm{b}$ are in fact related to adduct ions formed with $\mathbf{2 b}$ and $\mathbf{3 b}$ and an unknown contaminant.

Oximes of non-symmetric carbonyls exist as two syn $(Z)$ and anti $(E)$ stereoisomers. Only one peak for each derivative was observed on our chromatograms. This suggests that $\mathbf{2 b}$ or $\mathbf{3 b}$ formed as a sole isomer or that, if any, the different isomers coeluted. As revealed by single-crystal $\mathrm{X}$-ray analysis, glyoxal dihydrazone $\left(\mathrm{H}_{2} \mathrm{NN}=\mathrm{C}-\mathrm{C}=\mathrm{NNH}_{2}\right)$, obtained by reaction of $\mathrm{GL}$ and hydrazine $\left(\mathrm{NH}_{2}-\mathrm{NH}_{2}\right)$, crystallizes in the s-anti, E, E conformation [42]. Carbon and nitrogen atoms were shown to be coplanar, allowing less steric hindrance and favoring conjugation along the molecular backbone. Obvious similarities between dioxime ethers and dihydrazone skeletons encourage us to hypothesize that $\mathbf{2 b}$ and $\mathbf{3 b}$ are largely present as their s-anti, E, $E$ isomers (Scheme 2).

No peaks demonstrating the presence of the mono-derivatives 2a and 3a were visible on the chromatograms. As detailed in Section 3.3.4, the complete transformation of $\mathbf{2 a}$ and $\mathbf{3 a}$ into $\mathbf{2} \mathbf{b}$ and 3b was not achieved in the present experiments. Compounds 2a and 3a conserve a free carbonyl group that renders the molecule sufficiently polar to coelute with other adducts or, more certainly, with the excess of $\mathbf{1}$. Nevertheless, as shown later in this paper, reaction completion leading exclusively to bis-derivatives was rendered possible by minor changes in reaction conditions. Taking the latter assertion into account, our results are in good agreement with the general observation that reaction of GL or MG with the classical DNPH reagent yields almost exclusively the bis-DNPH derivative [43-46]. Otherwise, more complex mixtures, containing numerous singly and doubly derivatized derivatives, seem to be obtained with oxyamino reagents $[34,47,48]$. In our case, even if co-elution of different isomers remains possible, observation of a single peak for $\mathbf{2 b}$ and $\mathbf{3 b}$ also greatly facilitate their quantification.

\subsection{Fluorescence properties of $\mathbf{2} \boldsymbol{b}$ and $\mathbf{3} \boldsymbol{b}$}

A qualitative inspection of the chromatogram in Fig. 1 shows that, for equivalent carbonyl concentrations, substantially smaller peaks were obtained for $\mathbf{2} \mathbf{b}$ and $\mathbf{3 b}$ than for $\mathbf{4}$. The alteration of the fluorescence emission of $\mathbf{2} \mathbf{b}$ and $\mathbf{3 b}$, presumably in relation with the bis-DNSAOA structure of these molecules, can be postulated. Fluorescence quenching may be caused by a wide variety of mechanisms [49], including intermolecular or intramolecular interactions between fluorophores (self-quenching). Changes in both total fluorescence and emission peak position have been observed with molecules bearing two interacting dansyl (DNS) moieties [50]. To verify this possibility, excitation and emission spectra of $\mathbf{2} \mathbf{b}, \mathbf{3 b}$ and, for comparison purposes, of $\mathbf{4}$ were recorded. Spectra were recorded using our LC-fluorescence setup by stopping the flow of the pump at the apex of the elution peak of the species to be studied (i.e. at $15.2 \mathrm{~min}$ for $\mathbf{2} \mathbf{b}$ and $18.7 \mathrm{~min}$ for $\mathbf{3 b}$ ). We are aware that this technique was not the most appropriate way to investigate the fluorescence properties of the DNSAOA derivatives, but synthesis, isolation and purification of pure $\mathbf{2} \mathbf{b}$ and $\mathbf{3 b}$ was not conceivable due to the limited quantity of DNSAOA at our disposal. We nevertheless want to point out that this approach was not so far different from a study of the pure isolated derivatives. Indeed, the method ensures that the optical cell contains only the eluent, the compound under study, and whatever compound that might coelute with the compound of interest. As shown in the MS study reported above, there does not seem to be any coeluting compound with $\mathbf{2 b}$ and 3b at least with a different $m / z$. Both $E$ and $Z$ isomers may however coelute, which we anyway do not care to separate as long as we can quantify them as a group. All excitation and emission spectra exhibited similar shapes and, as expected for eluents with a $\sim 50 / 50$ $\mathrm{H}_{2} \mathrm{O} / \mathrm{CH}_{3} \mathrm{CN}$ composition [37], optimum excitation ( $\left.\lambda_{\text {ex }}\right)$ and emission $\left(\lambda_{\text {em }}\right)$ wavelengths lied in the $330-340 \mathrm{~nm}$ and $530-540 \mathrm{~nm}$ 

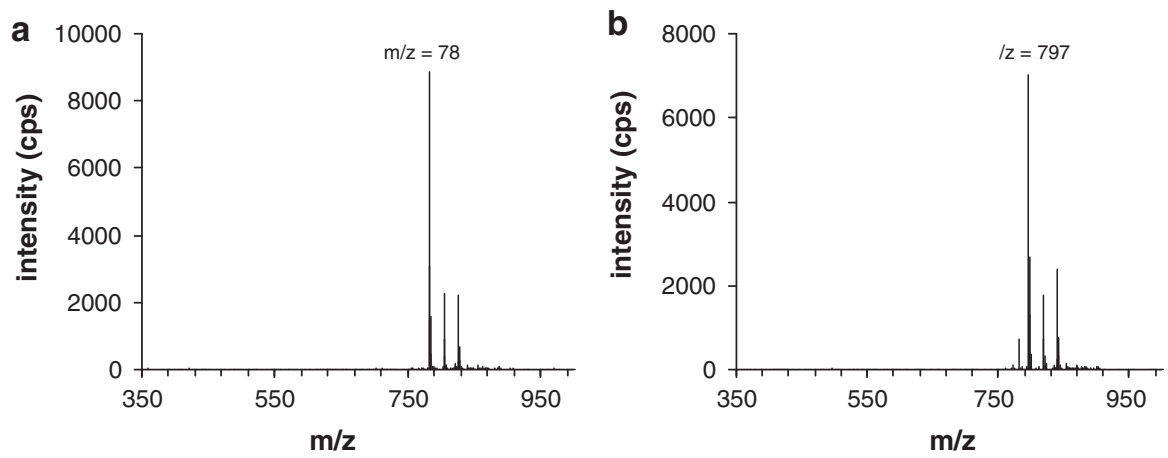

Fig. 2. Positive ion electrospray full-scan mass spectra of peaks eluting at $15.2 \mathrm{~min}$ (a) and $18.7 \mathrm{~min}$ (b).

ranges, respectively. It is worth noting that no spectral shifts for $\lambda_{\text {ex }}$ and $\lambda_{\text {em }}$ were observed for $\mathbf{2 b}$ and $\mathbf{3 b} v s \mathbf{4}$. Single excitation and emission wavelengths can therefore be used along the whole chromatogram and, in this study, further use of $\lambda_{\text {ex }}$ and $\lambda_{\text {em }}$ of 330 and $530 \mathrm{~nm}$ will be made. If the technique used to record the spectra does not allow a precise determination of the emission efficiencies of each adduct, qualitative comparison of the different spectra did not indicate any major loss or gain of fluorescence emission among $\mathbf{2 b}, \mathbf{3 b}$ and $\mathbf{4}$. Our results highlight that both DNS units in $\mathbf{2 b}$ and 3b are not in close interaction and, in particular, strong $\pi$ stacking interactions of the naphthalene rings can be ruled out. This reinforces our hypothesis that these derivatives exhibit a conformation characterized by the separation of the two DNS units. The DNSAOA design includes an acetamido brigde linking the $-\mathrm{ONH}_{2}$ function to the DNS moiety [37,38]. This limits the influence of the nature of the reacting carbonyl compound on the fluorophore properties but, in our case, also separates the two DNS groups, thus limiting potentially adverse self-quenching. This structural particularity of $\mathbf{1}$ is clearly an asset for our method, especially when measuring $\alpha$ DCs. We concluded that the difference in the peak intensities observed in Fig. 1 among $\mathbf{2 b}, \mathbf{3 b}$ and $\mathbf{4}$ cannot be explained by their intrinsic fluorescence emission features. Instead, reactivity differences between $\alpha$ DCs and FA may explain this observation and the following sections aim to provide a better understanding of the reaction patterns of 1 with GL and MG.

\subsection{Reactivity of $\mathbf{1}$ with GL and MG}

\subsubsection{Preliminary calibration experiments}

Oxyamino reagents are known to be more reactive than hydrazino ones [51]. Whereas [reagent]/[ $\Sigma$ aldehydes] molar ratios higher than 100 and acidic catalysis are generally required with hydrazino reagents such as DNPH, Houdier et al. [37,38] showed that [DNSAOA] $/[\Sigma$ aldehydes] ratios in the $10-20$ range were sufficient to ensure complete derivatization of the $\mathrm{C} 1-\mathrm{C} 4$ aliphatic aldehydes present in low content samples, even without any $\mathrm{H}^{+}$ catalyst addition. Preliminary calibration experiments were thus performed following conditions set out by Houdier et al. by preparing standard solutions of $\mathbf{1}(6.9 \mu \mathrm{M})$ spiked at levels of $20-160 \mathrm{nM}$ for GL, MG and FA. Linear regression slopes $\left(R^{2}\right)$ of $0.49 \times 10^{10}$ (0.993) and $0.56 \times 10^{10} \mathrm{M}^{-1}(0.989)$ for GL and MG, respectively, were measured after $36 \mathrm{~h}$ reaction time. Noticeably, these values were found to be significantly lower than that obtained for FA i.e. $3.56 \times 10^{10} \mathrm{M}^{-1}(0.992)$. Subsequent reanalyzes of the latter solutions showed that, while reaction between $\mathbf{1}$ and FA has reached completion after two days (identical calibration slopes, $R^{2}>0.995$ ), this was not the case with GL and MG for which calibration coefficients were shown to increase with increasing reaction times. However, due to repeated contacts between the reacting solutions and the air laboratory, contamination occurred and poor $R^{2}$ were obtained for the calibration curves. Consequently, it was not possible to evaluate satisfactorily the completion time for these reactions. Equilibrium between reactive and unreactive forms of GL/MG and/or inherent reactivity differences may explain the differences we observed between $\alpha$ DCs and FA. These hypotheses are examined below.

\subsubsection{Testing for the presence of unreactive forms of GL and MG in dilute solutions}

As shown in Scheme 3 for GL, carbonyl compounds in aqueous solution easily react with water to form partially or fully hydrated monomers [6]. In the case of GL and MG, hydrated monomers can subsequently form acetal or hemiacetal oligomers (mainly dimers and trimers) [52-54]. All these compounds are unreactive toward 1. Evaluating the reactivity of carbonyls with $\mathbf{1}$ therefore requires the understanding of their degree of hydration and oligomerization. Oligomers are likely to be present in the $40 \%$ (w/w) commercial solutions used to prepare the $10^{-3} \mathrm{M}$ stock solutions of GL and MG. To ensure that hydrolysis of the oligomers can happen, these stock solutions were left to stand for days before use. Hydration constants $\left(K_{\mathrm{h}}=[\Sigma\right.$ hydrate monomers]/[free carbonyl]) of $2.3 \times 10^{3}, 2.2 \times 10^{5}$ and $2.7 \times 10^{3}$ have been reported for FA, GL and MG, respectively [6]. At low concentration, hydrated monomers thus largely dominate the carbonyl free form (i.e. the reactive form). This explains why a strong excess of derivatizing reagent is necessary to displace the equilibria in Scheme 3 and to obtain full derivatization of the carbonyls. Assuming equivalent intrinsic reactivity for $\mathrm{FA}, \mathrm{GL}$ and $\mathrm{MG}$ toward 1, the proximity between $K_{\mathrm{h}}(\mathrm{FA})$ and $K_{\mathrm{h}}(\mathrm{MG})$, and the two orders of magnitude higher value for $K_{\mathrm{h}}(\mathrm{GL})$ should have led to similar slopes in the calibration curves for FA and MG and to a lower slope for GL. As reported in Section 3.3.1, different patterns are observed. These results lead us to assume that the differences observed do not result from insufficient excess of $\mathbf{1}$, but are more probably due to a lack of reactivity of GL and MG in comparison to FA.

\subsubsection{Effect of acid catalysis}

The apparent poor reactivity of $\mathbf{1}$ with GL and MG contrasts with its relatively high reactivity with single aldehydes. Indeed, derivatization of FA or AA in even nM snow samples was possible within a day and did not require any form of catalysis [10,14,38]. Interestingly, Lapolla et al. [47], using the oxyamino $O$-(2,3,4,5,6-pentafluoro-benzyl)hydroxylamine reagent, successfully performed derivatization of GL and MG at $\mathrm{pH}$ 3. They did not justify their choice, but the obvious similarities between the latter molecule and DNSAOA led us to investigate the effect of $\mathrm{H}^{+}$ catalysis on the reaction of 1 with GL and MG. Fig. 3 shows that acidification of the reacting mixture by $\mathrm{H}_{2} \mathrm{SO}_{4}$ results in significantly better yields for $\mathbf{2 b}$ and $\mathbf{3 b}$. Optimum conditions were obtained for $\mathrm{H}_{2} \mathrm{SO}_{4}$ concentrations of 1.5 and $5 \mathrm{mM}$ resulting in a factor 


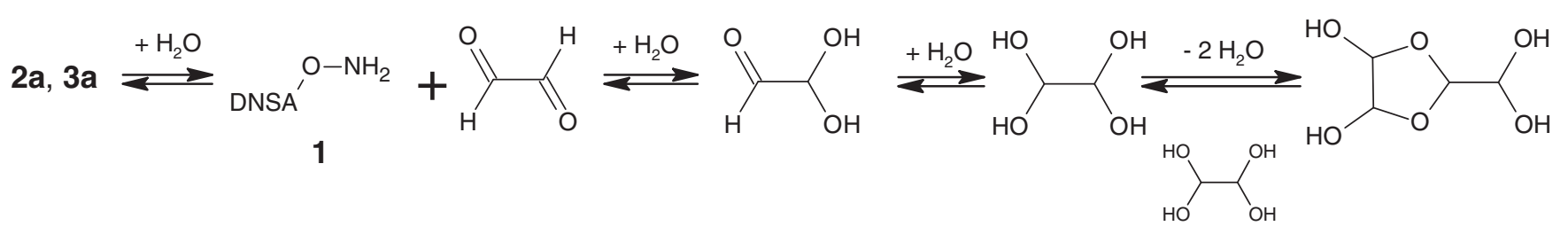

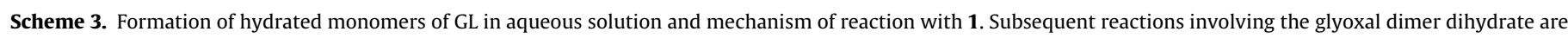
not shown.

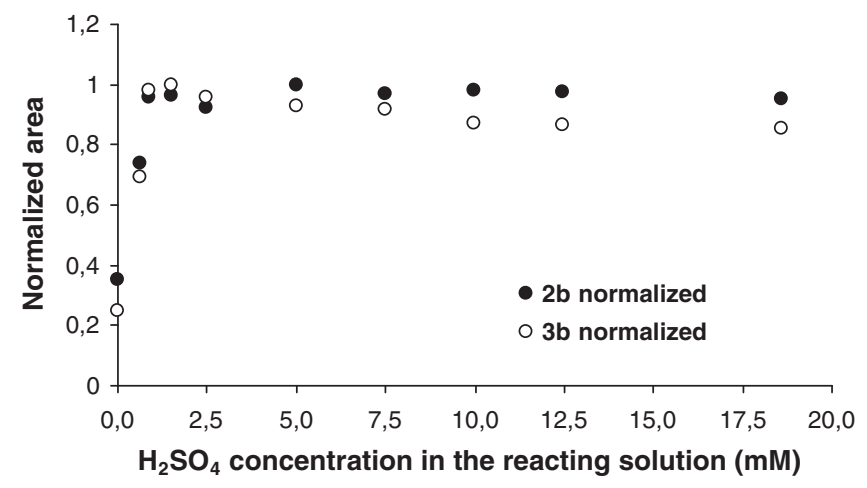

Fig. 3. Acidification of the reacting solutions and effect on the peak area of $\mathbf{2} \mathbf{b}$ and 3b measured after $36 \mathrm{~h}$ reaction times. Areas were normalized to the largest peak area observed. Initial conditions: $[\mathrm{GL}]=71 \mathrm{nM},[\mathrm{MG}]=81 \mathrm{nM},[\mathrm{DNSAOA}]=2.6 \mu \mathrm{M}$.

of 2.8 and 4.1 higher peak areas than in the absence of catalysis for $\mathbf{2 b}$ and $\mathbf{3 b}$, respectively. Calibration experiments were carried out using the same reactant concentrations as in the preliminary experiments described in Section 3.3.1, but after acidification of the reacting solutions $\left(\left[\mathrm{H}_{2} \mathrm{SO}_{4}\right]=2.5 \mathrm{mM}\right)$. It is to be noted that the chromatograms obtained did not show any emergence of new peaks and that any retention time shifts for the peaks attributed in 3.1 to $\mathbf{2 b}$ and 3b were observed. This let us to conclude that the compounds synthesized through derivatization in acidic media were actually those characterized in Section 3.1 i.e. compounds $\mathbf{2 b}$ and $\mathbf{3 b}$. Linear regression slopes $\left(R^{2}\right)$ of $1.35 \times 10^{10}(0.994), 2.02 \times 10^{10}(0.991)$ and $3.62 \times 10^{10} \mathrm{M}^{-1}(0.994)$ were inferred from the curves obtained for 2b, 3b and 4, respectively. Comparison between the uncatalyzed and catalyzed experiments shows that, while the slopes for $\mathbf{4}$ are similar, thereby confirming complete derivatization of FA, $\mathbf{2} \mathbf{b}$ and 3b slopes are enhanced by a factor of 2.8 and 3.6, respectively. We tested that, under acidic conditions, increasing the concentration of $\mathbf{1}$ up to a [DNSAOA] $/[\Sigma$ aldehydes] molar ratio of 50 did not lead to any increase in the calibration slopes, confirming that a ratio of 10 was sufficient to reach completion

\subsubsection{Kinetic experiments}

Reaction kinetics for the derivatization of GL and MG by $\mathbf{1}$ were determined with the aim of evaluating the appropriate reaction times, but also to provide preliminary clues for the understanding of the mechanism of $\mathrm{H}^{+}$catalysis. Experiments were carried out at room temperature $\left(18^{\circ} \mathrm{C}\right)$ in the presence or absence of $\mathrm{H}^{+}$catalysis $\left(\left[\mathrm{H}_{2} \mathrm{SO}_{4}\right]=2.5 \mathrm{mM}\right)$ by using initial GL and MG concentrations of $c a$. $0.15 \mu \mathrm{M}$. Concentration of $\mathbf{1}$ was $6.75 \mu \mathrm{M}$ for catalyzed reactions, and was increased to $50 \mu \mathrm{M}$ for uncatalyzed reactions in order to compensate for the anticipated longer reaction times. Formations of $\mathbf{2} \mathbf{b}$ and $\mathbf{3 b}$ were monitored as a function of time by LC analysis. Fig. 4 presents the curves that were obtained for the catalyzed experiments. Time evolution for the formation of $\mathbf{4}$ was also plotted for comparison purposes. If the time evolution of $\mathbf{4}$ displays a typical pseudo-first-order (PFO) kinetics plot, the upward curvature of the 2b and 3b concentration curves observed at short reaction times reveals that their formations display the kinetic behavior of two

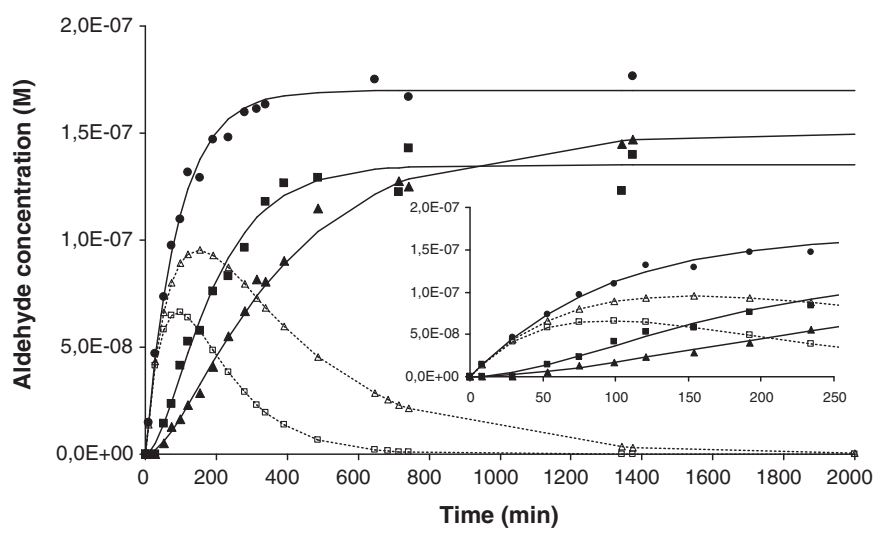

Fig. 4. Rate of formation of $\mathbf{2 b}(\mathbf{b}), 3 \mathbf{b}(\mathbf{\Delta})$ and $\mathbf{4}(\mathbf{})$ at $18{ }^{\circ} \mathrm{C}$ in presence of $\mathrm{H}^{+}$ catalysis $\left(\left[\mathrm{H}_{2} \mathrm{SO}_{4}\right]=2.5 \mathrm{mM}\right)$. Solid lines are the theoretical curves giving the best fits with experimental data. Open symbols $(\square, \Delta)$ are the calculated concentrations for mono-derivatives 2a and 3a, respectively. Initial concentrations (in $\mu \mathrm{M})$ : $[\mathrm{FA}]=0.17$, $[\mathrm{GL}]=0.14,[\mathrm{MG}]=0.15,[\mathrm{DNSAOA}]=6.75$.

consecutive reactions. To the best of our knowledge, such kinetics have never been reported for the derivatization of dicarbonyls, even with the classical DNPH reagent with which only PFO kinetics have ever been described $[44,55]$. The kinetics of consecutive reactions for GL and MG can be summarized as follows:

$\mathrm{GL} \stackrel{k_{1}}{\longrightarrow} \mathbf{2 a} \stackrel{k_{2}}{\longrightarrow} \mathbf{2 b}$

$\mathrm{MG} \stackrel{k_{3}}{\longrightarrow} \mathbf{3 a} \stackrel{k_{4}}{\longrightarrow} \mathbf{3 b}$

where $\left\{k_{1}, k_{2}\right\}$ and $\left\{k_{3}, k_{4}\right\}$ are the rate constants for the formation of $\{\mathbf{2 a}, \mathbf{2} \mathbf{b}\}$ and $\{\mathbf{3 a}, \mathbf{3} \mathbf{b}\}$, respectively. Assuming that each step is irreversible and first order with respect to the reactant, the time evolution of $\mathbf{2 a}$ and $\mathbf{2 b}$ concentrations can be expressed by Eqs. (1) and (2), where $[G L]_{0}$ is the initial concentration of $\mathrm{GL}$ :

$[\mathbf{2 a}]=\frac{[\mathrm{GL}]_{0} k_{1}\left(e^{-k_{1} t}-e^{-k_{2} t}\right)}{k_{2}-k_{1}}$
$[\mathbf{2 b}]=[\mathrm{GL}]_{0} \frac{1-\left(k_{2} e^{-k_{1} t}-k_{1} e^{-k_{2} t}\right)}{k_{2}-k_{1}}$

Equivalent Eqs. (3) and (4) describing the time evolution of 3a and $\mathbf{3 b}$ concentrations, respectively, and involving $k_{3}$ and $k_{4}$ can be written for MG. Curve fitting $\mathbf{2 b}$ and $\mathbf{3 b}$ measured concentrations to predicted values obtained through Eqs. (2) and (4), was used to derive the $\left\{k_{1}-k_{4}\right\}$ and $\left\{k_{1}^{\prime}-k_{4}^{\prime}\right\}$ PFO constants reported in Table 2, where unprimed and primed constants refer to $\mathrm{H}^{+}$ catalyzed and uncatalyzed kinetics, respectively. Best fits were obtained by minimizing the sum of absolute errors (SAE) between experimental and predicted values. At this stage it is important to point out that switching $k_{1}$ and $k_{2}$ or $k_{3}$ and $k_{4}$ in Eqs. (2) and (4) would lead to strictly identical theoretical curves. The possibility to determine $\left\{k_{1}, k_{2}\right\}$ and $\left\{k_{3}, k_{4}\right\}$ by using Eqs. (1) and (3), would have more efficiently constrained our constant determination by the mere Eqs. (2) and (4). Regrettably, mono-adducts 2a and 3a were not measurable on our chromatograms (see Section 3.1) and 
Table 2

PFO $\left(k_{i}, k_{i}^{\prime}\right)$ and corresponding second order $\left(k_{i}^{\mathrm{II}}, k_{i}^{\prime \prime \prime}\right)$ rate constants calculated for $\mathrm{H}^{+}$catalyzed and uncatalyzed reactions of 1 with GL and MG

\begin{tabular}{|c|c|c|c|c|c|c|}
\hline \multirow[t]{2}{*}{ Reaction } & \multicolumn{3}{|c|}{ Acid catalyzed kinetics ${ }^{\mathrm{a}}$} & \multicolumn{3}{|c|}{ Uncatalyzed kinetics ${ }^{\mathrm{b}}$} \\
\hline & $k_{i}\left(\min ^{-1}\right)$ & $\mathrm{SAE}^{\mathrm{c}}$ & $k_{i}^{\mathrm{II}}\left(\mathrm{M}^{-1} \min ^{-1}\right)$ & $k_{i}^{\prime}\left(\min ^{-1}\right)$ & $\mathrm{SAE}$ & $k_{i}^{\prime \prime I}\left(\mathrm{M}^{-1} \min ^{-1}\right)$ \\
\hline $\mathrm{GL} \rightarrow \mathbf{2 a}$ & $k_{1}=0.0135$ & 8.4 & $k_{1}^{\mathrm{II}}=2007$ & $k_{1}^{\prime}=0.0169$ & 5.7 & $k_{1}^{\prime \text { II }}=338$ \\
\hline $\mathbf{2 a} \rightarrow \mathbf{2 b}$ & $k_{2}=0.0076$ & $(n=17)$ & $k_{2}^{\mathrm{II}}=1130$ & $k_{2}^{\prime}=0.0155$ & $(n=10)$ & $k_{2}^{\prime I I I}=310$ \\
\hline $\mathrm{MG} \rightarrow \mathbf{3 a}$ & $k_{3}=0.0124$ & 4.2 & $k_{3}^{[I I}=1843$ & $k_{3}^{\prime}=0.0148$ & 9.5 & $k_{3}^{\prime I I}=296$ \\
\hline $\mathbf{3 a} \rightarrow \mathbf{3 b}$ & $k_{4}=0.0030$ & $(n=17)$ & $k_{4}^{\mathrm{II}}=446$ & $k_{4}^{\prime}=0.0124$ & $(n=10)$ & $k_{4}^{\prime \prime I}=248$ \\
\hline
\end{tabular}

a $[\mathbf{1}]=6.75 \mu \mathrm{M}$

b $[\mathbf{1}]=50 \mu \mathrm{M}$.

c $\mathrm{SAE}$ in $10^{-8} \mathrm{M}$; $n$ : number of data points considered in curve fitting.

concentrations for 2a and 3a plotted in Fig. 4 were calculated by transposing the corresponding rate constants into Eqs. (1) and (3). Nevertheless, fairly close fits between observed and calculated $\mathbf{2 b}$ and $\mathbf{3 b}$ concentrations were obtained. We thus believe that the rate constants reported here provide a reasonable representation of the relative reactivities of GL and MG, but also that they clearly depict the influence of $\mathrm{H}^{+}$catalysis on the kinetics of $\mathbf{1}$ with $\alpha \mathrm{DCs}$.

To assign $k_{i}$ values to the correct reactions, we considered structure-reactivity relationships. Given the less reactive nature of the keto carbonyl of MG, we expect that the first step in the derivatization of MG proceeds by the nucleophilic attack of 1 on the aldehydic carbon of MG, yielding 3a. We thus assumed $k_{3}>k_{4}$. Both carbonyl carbons involved in the reactions leading to $\mathbf{2 a}$ and $\mathbf{3 a}$ are of the same aldehydic nature and we expect $k_{1}$ to have a value close to that of $k_{3}$ i.e. $0.0124 \mathrm{~min}^{-1}$. Finally, we calculated that, under acidic conditions, reaction times of $\sim 12$ and $27 \mathrm{~h}$ were necessary to reach a $95 \%$ completion for GL and MG, respectively. Calculations for 2a and 3a confirm that very low residual concentrations are expected for these adducts at such reaction times (Fig. 4).

To facilitate comparison between catalyzed and uncatalyzed experiments, second order rate constants $k_{i}^{\mathrm{II}}$ and $k_{i}^{\prime \text { II }}$, obtained by dividing PFO constants by the concentration of $\mathbf{1}$, are reported in Table 2 . As highlighted by the systematically higher $k_{i}^{\text {II }}$ constants, $\mathrm{H}^{+}$catalysis seems to be effective for both GL and MG and for both consecutive reactions. Interestingly, the highest catalytic efficiency was observed for the first reaction step that leads to $\mathbf{2} \mathbf{a}$ and $\mathbf{3 a}$, with $k^{\mathrm{II}} / k^{\prime I I}$ ratios of 5.9 and 6.2 , respectively. To better compare with catalyzed experiments, we used our $k_{i}^{\prime \prime l}$ constants and assumed a concentration of 1 of $6.75 \mu \mathrm{M}$ to calculate $95 \%$ reaction times of $\sim 36$ and $43 \mathrm{~h}$ for GL and MG, respectively. Rather long reaction times are thus required to ensure derivatization completion without $\mathrm{H}^{+}$catalysis and are likely to explain why MG and GL give smaller peaks relative to that of FA in the chromatogram of Fig. 1. Indeed, the 1 concentration was only $5 \mu \mathrm{M}$ in these experiments, and even longer reaction times would have been necessary to fully derivatize GL and MG.

\subsection{LC conditions for concomitant separation of $H A, G L, M G$ and single carbonyls}

HA has rarely been measured in environmental water samples. A simple explanation for this lies in the fact that this molecule was not systematically sought, but also that it is difficult to identify on chromatograms. Indeed, using Isocratic Mode LC conditions (49/51 (v/v) $\mathrm{H}_{2} \mathrm{O} / \mathrm{CH}_{3} \mathrm{CN}$ ), addition of $\mathrm{HA}$ to a solution of $\mathbf{1}$ resulted in an unchanged chromatogram. Compound $\mathbf{5}$ bears a free hydroxyl function which makes the molecule sufficiently polar to coelute with 1. Although we achieved separation of $\mathbf{1}$ and $\mathbf{5}$ by using isocratic elution with $\mathrm{H}_{2} \mathrm{O} / \mathrm{CH}_{3} \mathrm{CN}$ binary eluents containing more than $65 \%$ $(\mathrm{v} / \mathrm{v})$ water, such a composition was not suitable for elution of the less polar GL and MG derivatives at reasonable retention times. Gradient elution mode was thus selected and several gradient programs were investigated with the aim of separating $\mathbf{1}$ and $\mathbf{5}$, but also

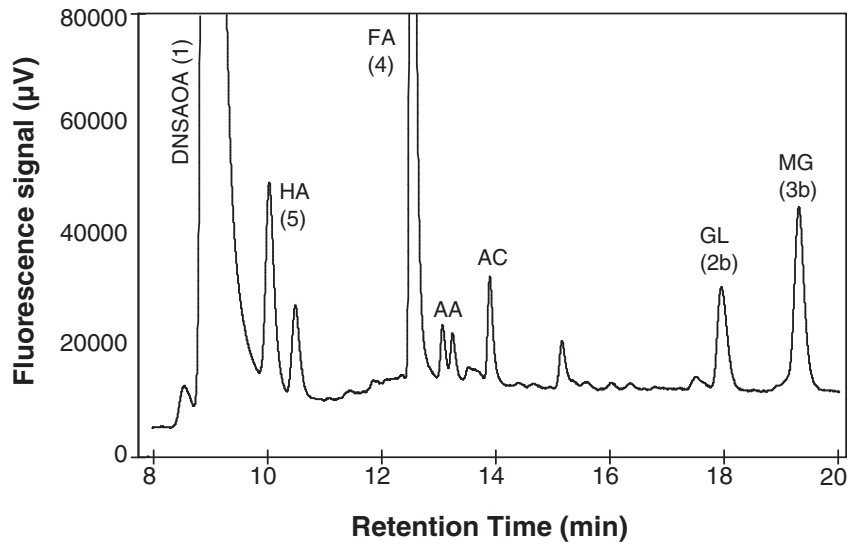

Fig. 5. Chromatogram of a mixture composed of $\mathbf{1}$ and DNSAOA oximes of HA, FA, AA, AC, GL and MG. LC conditions: Gradient Mode. Fluorometer gain: 100.

to allow the simultaneous measurement of GL, MG and of single carbonyls within the shortest time. The best compromise between separation of the different adducts and run length was obtained by running the gradient program fully described in Section 2.4 As shown in Fig. 5, 1 and $\mathbf{5}$ ( $Z+E$ isomers) separate well. DNSAOA adducts of FA (4), AA and AC separate in the 12.5-14.5 min range and those of GL and MG in the 18-20 min range.

\subsection{Reactivity of HA with 1}

Kinetics for the formation of 5 were determined at $18^{\circ} \mathrm{C}$ using concentrations of $\mathrm{HA}$ and 1 of 0.15 and $6.75 \mu \mathrm{M}$, respectively The time-evolution of the peak area of $\mathbf{5}$ (sum of the $Z+E$ peaks) showed a plot characteristic of first order kinetics. PFO and second order constants of 0.0072 and $0.0030 \mathrm{~min}^{-1}$ and of 1070 and $446 \mathrm{M}^{-1} \mathrm{~min}^{-1}$ were derived from the plots obtained for the $\mathrm{H}^{+}$catalyzed and uncatalyzed reactions, respectively. A 95\% completion time of $6.9 \mathrm{~h}$ in catalyzed experiments, less than that of GL at equivalent concentrations of $\mathbf{1}$, was calculated. Although the factor of 2.4 between uncatalyzed and catalyzed rate coefficients was lower than that measured for GL and MG, this result contradicts what we observed for FA. As observed with $\alpha$ DCs, compounds belonging to the hydroxyaldehyde family seem to exhibit reactivity patterns different from those of simple aldehydes, strengthening the need for further studies if one aims to correlate the structure of single or polyfunctional carbonyls to their reactivity.

\subsection{Summary of reactivity studies and discussion}

To summarize, derivatization of GL, MG and HA by 1 clearly benefits from the addition of $\mathrm{H}^{+}$catalyst to the reacting solution. Using concentrations of 1 of $6.75 \mu \mathrm{M}$, derivatization of mixtures of GL, MG and HA is complete after $c a$. one day reaction. Although the reactivity of FA appears to be higher in non-acidified media, curves in Fig. 4 show that completion time for FA in acidic conditions remains 
shorter than that of GL and MG. In practice, analysis of low concentrated samples were carried out by using concentrations of $\mathbf{1}$ in the 3-10 $\mu \mathrm{M}$ range and we allowed reaction mixtures to react $c a .36 \mathrm{~h}$ at room temperature to ensure the full derivatization of all carbonyls. Being inversely related to the concentration of the excess reagent, reaction times could be shortened by using higher concentrations of $\mathbf{1}$. The upper limit to which the $\mathbf{1}$ concentration may be increased is defined by the ratio between the amount of contaminants carried by the solution of $\mathbf{1}$ and the amount of carbonyls in the sample to analyze (see Section 3.7.3). The main contaminant is generally compound $\mathbf{4}$, which concentration in the $\mathbf{1}$ solution often limits the use of 1 to concentrations less than $10 \mu \mathrm{M}$ to permit the analysis of nM-level samples. DNSAOA concentrations in the $0.1-1 \mathrm{mM}$ range can potentially be employed for the determination of $\mu \mathrm{M}$ level samples, yet providing reaction times from a few hours to less than $1 \mathrm{~h}$. DNSAOA is not commercially available and is a relatively costly molecule. This is the reason why we chose to dilute our concentrated samples (cloud water, brine and FF samples) rather than to use elevated concentrations of $\mathbf{1}$. Increasing temperature will obviously also accelerate the derivatization reaction. This has already been demonstrated for the reaction of a structural analogue of DNSAOA with acetone [37]. Preliminary tests using $\mathbf{1}$ and sub$\mu \mathrm{M}$ concentrations of carbonyls at temperatures of $\mathrm{ca} .60^{\circ} \mathrm{C}$ were performed following this idea but they were inconclusive due to impeding contaminations by FA and AA, probably originating from the vial caps at those temperatures. The use of vial caps without septa may be a response to this issue (work in progress).

\subsection{Method validation and sensitivity studies}

Being interested in polar snow analysis, sensitivity was a parameter we specifically sought to optimize. The validity of the method in terms of linearity and accuracy was thus tested at concentration levels relevant to this particular requirement. Because it ensures satisfactory LC separation of $\alpha O C s$ and single carbonyls, these studies were performed with the Gradient Mode conditions described above.

\subsubsection{Linearities}

To overcome possible matrix effects, the standard addition method was used for calibration. The linear regressions for $\mathbf{2 b}, \mathbf{3 b}, \mathbf{4}$ and $\mathbf{5}$ reported in Table 3 were established by spiking volumes of a solution containing almost equivalent concentration $(c a .10 \mu \mathrm{M})$ of each carbonyl of interest to a snow sample. They were established over the 7-170 and $13-270 \mathrm{nM}$ ranges for $\alpha \mathrm{OCs}$ and FA, respectively. For these experiments, the concentration of 1 was $5 \mu \mathrm{M}$ and the electronic gain of the fluorometer was set to 1000 to favor a high sensitivity. As shown in Table 3, all calibration curves showed good $R^{2}$ values ( $>0.995$ ). Calibration slopes for $\mathbf{2 b}, \mathbf{3 b}$ and $\mathbf{4}$ ranged from 1.8 to $4.3 \times 10^{11} \mathrm{M}^{-1}$. The linearity has also been verified for each carbonyl and for concentrations up to $1.5 \mu \mathrm{M}$. To avoid detector saturation, the fluorometer gain was lowered to 100 , and slopes a factor of $c a$. ten times lower than that at gain 1000 were measured. The peak areas used to determine the regressions were those measured for the spiked mixtures to which were subtracted the areas measured for the unspiked $(0 \mu \mathrm{L}$ addition) solution. This removes the contribution of the sample used for the calibration experiment and allows the direct use of the regression equations to calculate the concentrations of unknown samples (provided that they are of similar nature and origin). In that case, the $y$-intercept of each calibration curve represents the initial contamination carried by $\mathbf{1}$. Here, for compound $\mathbf{4}$, it represents $14 \mathrm{nM}$ i.e. less than $0.3 \%$ of the initial concentration of $\mathbf{1}$. The intercepts of the calibration curves for $\mathbf{2 b}, \mathbf{3 b}$ and $\mathbf{5}$ varied only slightly from zero, illustrating the absence of contamination due to the 1 solution (see Section 3.7.3). These spiked experiments were reproduced for each type of sample we

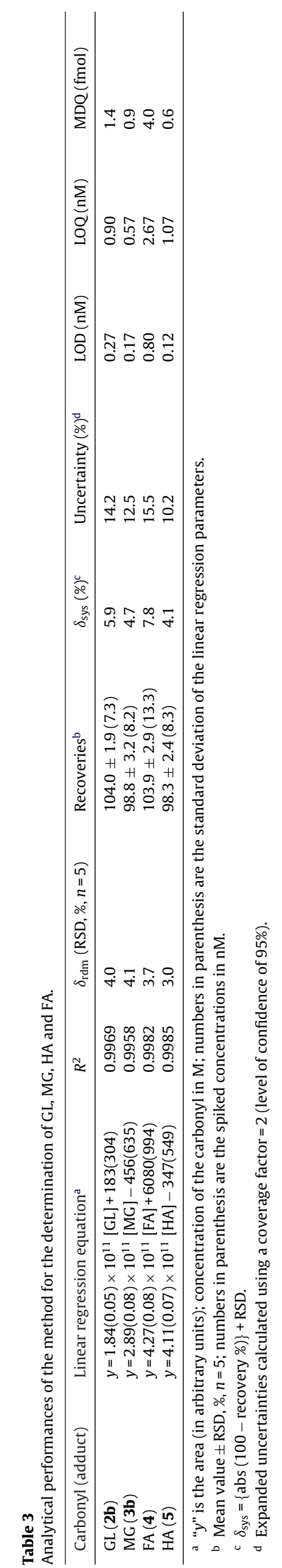


analyzed (i.e. polar snow, alpine snow, rain, etc.) and linear regressions showed consistently good linearity. This was true for all types of samples studied, including highly concentrated and saline brine and frost flowers samples. Similar slopes were also obtained when direct calibrations using standard made of purified water were performed. These results support the idea that the derivatization was not influenced by concomitants present in those natural samples. Furthermore, as spiked solutions were made of equivalent concentrations of each carbonyl, the fact that good linearities were observed for each calibration curve let us to conclude that derivatization of a given carbonyl has no manifest influence upon the analysis of the other carbonyls.

\subsubsection{Measurement uncertainty}

Random and systematic errors associated with the analytical procedure were determined to evaluate the relative measurement uncertainty of the method. Results are summarized in Table 3. Random errors (precision) may result from the preparation of the reacting solution, the derivatization reaction itself, variations of the eluent composition, fluctuations of the fluorometer lamp intensity and imprecision in peak integration. This type of error (subsequently referred as $\delta_{\text {rdm }}$ ) was evaluated through the assay of five identical solutions of a melted snow sample. Description of this sample and carbonyl levels are reported in Table 5 (sample c). The relative standard deviation (RSD) of the concentrations calculated by using the linear regressions detailed in Table 3 was less than $4.1 \%$ for all targeted compounds. A RSD of $4.0 \%$ at the $7 \mathrm{nM}$ level was calculated for GL. This value is statistically equivalent and compares favorably to the RSD of $7 \%(20 \mathrm{nM})$ and $5.4 \%(30 \mathrm{nM})$ reported by Takeda et al. [25] and Kieber and Mopper [20]. Systematic errors (bias, $\delta_{\text {sys }}$ ) were determined from the quintupled assay of the same snow sample spiked at concentration levels of 7.3, 8.2, 13.3 and $8.3 \mathrm{nM}$ for GL, MG, FA and HA, respectively. Systematic errors were expressed in terms of recovery percentage of the theoretical concentrations. Recoveries (mean values) were found to lie in the range 98.3-104.0\% and were used to calculate $\delta_{\text {sys }}$ as the deviation from $100 \%$ to which was added the RSD of the corresponding recovery. Taking into account both types of errors and assuming these to be independent, standard uncertainties were calculated as the square root of the sum of the squares of both error types. Values reported in Table 3 are the relative expanded uncertainties scaled by using a coverage factor of 2 , which gives a level of confidence of $c a .95 \%$. Uncertainties range from $10.2 \%$ for HA to $15.5 \%$ for FA. We are aware that these values are specific both to the studied concentration level (here 7-8 nM for $\alpha \mathrm{OCs}$ ) and to snow samples. Spiked experiments described in Section 3.7.1 show that neither significant deviations from linearity nor $y$-intercepts strongly deviating from zero were observed. This was also the case for saline samples (once diluted) and this let us to assume that their compositions have only a limited impact on the method's accuracy.

\subsubsection{Sensitivity}

A major factor in determining the sensitivity of the method is the contamination level of the $\mathbf{1}$ solution added to the analyzed sample. Contamination generally occurs while synthesizing $\mathbf{1}$ by acid deprotection of its precursor, DNSAOA-t-butyloxycarbamate [38]. Indeed, solvents used may contain carbonyls but may also solubilize atmospheric carbonyls during the reaction. The level of contamination was determined for a given 1 solution, before its use for analytic purposes, as described in ref. [38]. FA is the main atmospheric carbonyl and this explains why we systematically observed contamination by 4 which ranged, depending on the deprotection experiment, between 0.1 and $1 \%$ of the concentration of $\mathbf{1}$. We never observed any contamination by $\mathbf{2 b}, \mathbf{3 b}$ or $\mathbf{5}$ of the solution obtained immediately after the deprotection step. The 1 solution was kept frozen and was thawed just before use.
By increasing the contact time between air and the $\mathbf{1}$ solution, freezing/thawing cycles resulted in increasing contamination levels for $\mathbf{4}$ but also in the apparition of traces of $\mathbf{2 b}$ or $\mathbf{3 b}$ never exceeding $0.5 \%$ of the concentration of $\mathbf{1}$. We never observed such contamination for $\mathbf{5}$. The limits of detection (LOD) and limits of quantification (LOQ) for GL, MG and HA were determined by deeming that the $\mathbf{1}$ solution contained no traces of $\mathbf{2 b}, \mathbf{3 b}$ and $\mathbf{5}$. They were estimated as the amounts for which the signal to noise ratio was $3: 1$ and 10:1, respectively. Due to systematic contamination of the DNSAOA solution by 4 , the LOD and LOQ for FA were defined as the equivalent concentration of 3 and 10 times the standard deviation of $n=5$ replicate analyses of the $13 \mathrm{nM}$ spiked solution described in Section 3.7.2. LOD and LOQ are reported in Table 3 along with minimum detectable quantities (MDQ) obtained by multiplying the LOD by the volume of the injection loop $(5 \mu \mathrm{L})$. The LOD (respectively MDQ) achieved were in the $0.1-0.3 \mathrm{nM}$ (0.6-1.4 fmol) range for $\alpha \mathrm{OCs}$ and was $0.8 \mathrm{nM}$ ( $4 \mathrm{fmol}$ ) for FA.

\subsubsection{Comparison with published sensitivities}

The intricacy in comparing our sensitivity values for $\alpha$ OCs to those found in existing publications lies in the fact that, for most techniques, the analysis of low content samples was rarely straightforward. Indeed, preconcentration of the samples implying either extraction by organic solvents [19,21,24,31,34], coated stir bars [29], C18-cartridges [20,23] or the use of a preconcentration column $[25,56]$ was often required to reach the desired sensitivity. Large injection volumes were also frequently used to compensate for the lack of sensitivity $[19,20,23,25,55]$. LOD values found in literature studies for a selection of methods along with their main features are reported in Table 4 . The highest sensitivities were reported by Zhou and Mopper [23], with LOD values as low as $0.05 \mathrm{nM}$ for both GL and MG. In that case, samples were derivatized by DNPH and pre-concentrated by a factor of 50 before LC analysis. Such preconcentration steps may render the analytical procedure somewhat tedious but can also generate some bias due to cumulative operations and possible loss of materials. The use of large injection volumes may also result in peak broadening, altering peak separation and quantitation. Advantageously, studies by Wang et al. [26], Hara et al. [28] and Igawa et al. [36] did not resort to preconcentration steps nor to large injection volumes. MDQ of 0.8 (GL) and $1.2 \mathrm{pmol}$ (MG) from Wang et al. probably represent the current limits of what can be expected from the use of the widespread DNPH-LC-UV technique. MDQ below $0.1 \mathrm{pmol}$ for both GL and MG were reported by Hara et al. who used fluorescent 1,2-diamino4,5-methylenedioxybenzene (DMB) as a derivatizing reagent. Nonetheless, this method is specific for $\alpha$ DCs and neither HA nor single aldehydes can be measured. Because they are straightforward techniques, sensitivities reported for the last cited methods can be directly compared to our values. The DNSAOA method indubitably exhibits higher sensitivities compared to the other methods. Our method clearly benefits from the intense fluorescence of $\mathbf{1}$, which also makes possible a simple analytical procedure and the use of relatively small sample (typically $1.5 \mathrm{~mL}$ ) and injection volumes $(5 \mu \mathrm{L})$. As illustrated by the lower LOD we obtained for FA, we wish to emphasize that such high sensitivities are strongly dependent upon the purity of the DNSAOA solution used, and that particular care has to be taken to preserve this solution.

\subsection{Application to natural samples}

The proposed method was applied to the determination of $\alpha \mathrm{OCs}$ and single carbonyls (for clarity, only FA levels are reported) in a series of samples chosen for their different origins and concentrations. Sample description and concentrations are summarized in Table 5. Over 250 samples were collected during the Ocean Atmosphere Sea Ice Snowpack (OASIS) intensive campaign held 
Table 4

Reported sensitivities for the measurement of GL, MG and HA in environmental water samples obtained from a selection of methods.

\begin{tabular}{|c|c|c|c|c|c|c|c|c|c|}
\hline \multirow[t]{2}{*}{ Study: authors [Ref] } & \multirow[t]{2}{*}{ Derivatizing Reagent } & \multirow[t]{2}{*}{ Detection method } & \multirow{2}{*}{$\begin{array}{l}\text { Analysis } \\
\text { duration } \\
\text { (min) }\end{array}$} & \multirow[t]{2}{*}{ Inj. vol. $(\mu \mathrm{L})$} & \multicolumn{3}{|c|}{ LOD in $\mathrm{nM}(\mathrm{MDQ})^{\mathrm{a}}$ in pmole } & \multirow[t]{2}{*}{ Preconcentration step } & \multirow[t]{2}{*}{ Application to } \\
\hline & & & & & $\overline{\mathrm{GL}}$ & MG & $\mathrm{HA}$ & & \\
\hline Gunz and Hoffmann [19] & DNPH & LC-UV & b & 500 & 80 & 10 & n.m. ${ }^{c}$ & Liquid extraction & Snow \\
\hline Zhou and Mopper [23] & DNPH & LC-UV & 18 & 2000 & 0.05 & 0.05 & n.m. & Cartridge extraction & Sea water \\
\hline Matsumoto et al. [24] & DNPH & LC-UV & 27 & b & 235 & 174 & 51 & Liquid extraction & Rain, fog water \\
\hline Takeda at al. [25] & DNPH & LC-UV & 50 & 100 & 3 & n.m. & n.m. & Preconcentr. column & Drinking water \\
\hline Wang et al. [26] & DNPH & LC-UV & 30 & $20-50$ & $40(0.8)$ & $60(1.2)$ & n.m. & No & Rain \\
\hline Hara et al. [28] & DMB & LC-FD & 5 & 10 & $8(0.08)$ & $7(0.07)$ & n.m. & No & No application \\
\hline Neng at al. [29] & DAN & LC-DAD & 10 & 20 & 0.25 & 0.35 & n.m. & Stir bar extraction & Tap water \\
\hline Kawamura [31] & $\mathrm{BF}_{3}$ & GC-FID & 16 & 50 & 0.86 & 0.69 & n.m. & Liquid extraction & Polar snow, rain \\
\hline Igawa et al. [36] & MBTH & LC-Vis. & 10 & 100 & $190(19)$ & $99(9.9)$ & $55(5.5)$ & No & Fog water \\
\hline Lee and Zhou $[55]^{\mathrm{d}}$ & DNPH & LC-UV & 25 & 1230 & $1.5(1.9)$ & $3.1(3.8)$ & $6.2(7.6)$ & No & Air (coil technique) \\
\hline This work & DNSAOA & LC-FD & 19 & 5 & $0.27(0.0014)$ & $0.17(0.0009)$ & $0.12(0.0006)$ & No & Snow, cloudwater \\
\hline
\end{tabular}

a MDQ are given only for methods that do not require any preconcentration step.

b Not mentioned.

c Not measured.

d See also Zhou et al. [56] for subsequent developments.

Table 5

\begin{tabular}{|c|c|c|c|c|c|c|c|c|c|}
\hline Sample & Type & Origin & Sampling date & HPLC mode & Dilution & {$[\mathrm{FA}] \mathrm{nM}^{\mathrm{a}}$} & {$[\mathrm{GL}] \mathrm{nM}$} & [MG] nM & {$[\mathrm{HA}] \mathrm{nM}$} \\
\hline$a_{1}$ & Surface snow & Barrow land & March 2009 & Isocratic & No & $98.9(5.7)$ & $37.1(3.3)$ & $6.5(0.9)$ & n.m. ${ }^{b}$ \\
\hline$a_{2}$ & Surface snow & Barrow land & March 2009 & Isocratic & No & $105.3(15.3)$ & $14.6(1.4)$ & $4.8(0.6)$ & n.m. \\
\hline$a_{3}$ & Precipitating snow & Barrow land & April 2009 & Gradient & No & 92.8 & 13.9 & 1.9 & 7.0 \\
\hline$a_{4}$ & Depth hoar $(-23 \mathrm{~cm})^{c}$ & Barrow land & March 2009 & Isocratic & No & $267.3(3.1)$ & $73.9(2.5)$ & $18.1(0.4)$ & n.m. \\
\hline$b_{1}$ & Frost flowers & Barrow sea ice & May 2009 & Isocratic & Yes & $5392.8(161.2)$ & $439.7(19.3)$ & $629.4(13.8)$ & n.m. \\
\hline$b_{2}$ & Frost flowers & Barrow sea ice & May 2009 & Gradient & Yes & 3298.9 & 114.0 & 112.0 & 351.5 \\
\hline$b_{3}$ & Brine on sea ice & Barrow sea ice & March 2009 & Isocratic & Yes & $1063.0(3.6)$ & $22.0(0.4)$ & $35.9(0.6)$ & n.m. \\
\hline $\mathrm{b}_{4}$ & Windpacked snow & Barrow sea ice & March 2009 & Isocratic & No & $87.8(13.5)$ & $20.4(1.0)$ & $3.3(1.2)$ & n.m. \\
\hline c & Alpine Snow $(-1 \mathrm{~m})^{c}$ & Col du Dômed & May 2009 & Gradient & No & 294 & 8.0 & 4.7 & 13.9 \\
\hline d & Rain & Grenoble $\mathrm{e}^{\mathrm{e}}$ & April 2010 & Gradient & Yes & 1155 & 14.0 & 11.0 & 25.7 \\
\hline$e_{1}$ & Cloud water & puy de Dôme ${ }^{\mathrm{f}}$ & Winter 2008-2009 & Gradient & Yes & 3260.1 & 359.6 & 23.3 & 730.7 \\
\hline $\mathrm{e}_{2}$ & Cloud water & puy de Dôme & Winter 2008-2009 & Gradient & Yes & 1748.3 & 420.6 & 385.0 & 1514.9 \\
\hline$e_{3}$ & Cloud water & puy de Dôme & Winter 2008-2009 & Gradient & Yes & 6977.0 & 2288.9 & 1099.4 & 2336.2 \\
\hline
\end{tabular}

a Values in parenthesis are the standard deviations calculated over triplicate samples. In this case, given concentrations are the average values

b Not measured.

c Sampling depth.

d Mont-Blanc range, France, $4250 \mathrm{~m}$ a.s.l.

e Sample was collected in the vicinity of the laboratory, Grenoble University campus, France.

f Centre of France, $1465 \mathrm{~m}$ a.s.l. 
in Barrow (Alaska) in winter 2009. The full dataset and a comprehensive interpretation of their significance in terms of atmospheric chemistry will be examined elsewhere. Analyses were performed in Barrow during the campaign, for practical reasons, Isocratic Mode was generally used during the campaign, which explains why HA was not systematically measured. To evaluate the snowpack spatial heterogeneity (mainly due to wind remobilization) some snow samples were tripled and standard deviations of their concentration distribution are reported. In clean air conditions and in the absence of any particular atmospheric phenomenon, concentrations of samples $a_{1-3}$ were typical of what we observed throughout the entire campaign for surface snow samples. In all samples, FA was found to be the dominant carbonyl, followed by GL and MG. To our knowledge, apart from the GL and MG concentrations reported by Kawamura [31] for a snow sample collected in Greenland, these data provide the first determination of GL, MG and HA (sample $a_{3}$ ) in polar snow. Our alpine snow sample (c) exhibits higher FA concentration than polar snow, but levels for $\alpha O C$ s were surprisingly lower than in samples $a_{1-4}$, raising the question of the sources of $\alpha O C s$ in these particular environments. It is noteworthy that, in a general manner, and especially during the OASIS campaign, we only measured very few samples with $\alpha O C$ concentrations below the LOQ of the method.

Frost flowers (FF) are highly saline (up to $100 \mathrm{~g} \mathrm{~L}^{-1} \mathrm{NaCl}$ ) ice crystals that grow on young sea ice. Elevated salinities $\left(>10 \mathrm{~g} \mathrm{~L}^{-1}\right)$ were shown to reduce the reactivity of $\mathbf{1}$ with carbonyls (Houdier and Barret, unpublished results). FF ( $\left.b_{1-2}\right)$ and brine $\left(b_{3}\right)$ samples were thus diluted by a factor of $c a$. 10 to reduce the salinity. Our data, which also provide the first measurements of the carbonyl content of FF and brine, are characterized by substantial concentrations for all carbonyls. Throughout their growth, FF wick up and concentrate the solutes present in the brine that generally covers the sea ice. This mechanism has been described to explain the elevated salinity of FF [57] and may provide explanations for the staggering concentrations we measured. The observation of greater carbonyl levels in FF than in brine gives credence to this hypothesis. Bacteria were also shown to be present at high levels in FF [58] and one cannot rule out the production of the carbonyls studied here through biological activity. Nevertheless, our FF data remain sparse and other field studies and laboratory experiments will be required to better understand the processes responsible for the remarkable concentrations we measured during this campaign.

Samples $e_{1-4}$ belong to a series of cloud water samples from continental origin collected at the puy de Dôme mountain (France) in the course of the winter 2008-2009. Concentration levels for FA, GL and MG have been reported in rain or cloud water, but only a few studies have accounted for HA concentrations [24,34]. As illustrated by samples $d$ and $e_{1-3}$, we generally found that HA concentrations were higher than the ones of GL and subsequently MG. This result corroborates those of Matsunaga and Kawamura [34] who interpreted the abundance of HA by the fact that it can form a cyclic hemiacetal dimer much less reactive toward oxidation than the free HA molecule. Neglecting other minor carbonyls such as AA or AC, $\alpha O C$ s contribute between 40 and $75 \%$ of the carbonyl carbon content of samples $e_{1-3}$. In the case of sample $e_{2}$, the contribution of HA to the carbonyl carbon content approaches $45 \%$. The knowledge of GL, MG and HA concentrations in cloud water is critical if one wants to understand the processes that will subsequently yield SOA. In particular, our results lead us to emphasize the importance of measuring HA when analyzing cloud water chemical composition with this aim in mind.

\section{Conclusions}

In the present study we improved the DNSAOA-LC-fluorescence method for the aqueous-phase measurement of three atmospherically relevant $\alpha$-oxygenated carbonyls: GL, MG and HA. Using $\mathrm{H}^{+}$catalysis to quicken the reaction of DNSAOA with GL, MG, and to a lesser extent with HA, our modified method enables the concomitant determination of $\alpha \mathrm{OCs}$ plus single carbonyls at the low nM level. The method is straightforward and, thanks to its low detection limits, does not require any preconcentration of tracelevel samples. This technique was applied to environmentally significant samples, confirming the abundance of $\alpha \mathrm{OCs}$ in cloud water and their presence in polar snow. Astonishing amounts of $\alpha O C s$ were also measured in frost flowers that develop on sea ice. In most samples studied, HA was shown to be the dominant $\alpha \mathrm{OC}$ and we emphasize that its measurement is not only relevant, but that it will be critical for further investigations dedicated to the understanding of the in-cloud processes involved in the formation of secondary organic aerosol.

\section{Acknowledgements}

This work was supported by the LEFE CHAT program of CNRSINSU and Université Joseph Fourier of Grenoble. We would like to thank the Auvergne region for the PhD grant to T. Charbouillot. We also thank Laurent Arnaud for assistance in recording fluorescence spectra, Delphine Six for sampling snow at the Col du Dôme and Annielle Tapper for her fruitful comments on the manuscript.

\section{References}

[1] B. Ervens, G. Feingold, G.J. Frost, S.M. Kreidenweis, J. Geophys. Res. 109 (2004) D15205

[2] A.G. Carlton, B.J. Turpin, K.E. Altieri, S. Seitzinger, A. Reff, H.-J. Lim, B. Ervens, Atmos. Environ. 41 (2007) 7588.

[3] T.-M. Fu, D.J. Jacob, F. Wittrock, J.P. Burrows, M. Vrekoussis, D.K. Henze, J. Geophys. Res. 113 (2008) D15303.

[4] M.J. Perri, S. Seitzinger, B.J. Turpin, Atmos. Environ. 43 (2009) 1487

[5] A.G. Carlton, C. Wiedinmyer, J.H. Kroll, Atmos. Chem. Phys. 9 (2009) 4987

[6] E.A. Betterton, M.R. Hoffmann, Environ. Sci. Technol. 22 (1988) 1415.

[7] X. Zhou, K. Mopper, Environ. Sci. Technol. 24 (1990) 1864

[8] K.E. Altieri, S.P. Seitzinger, A.G. Carlton, B.J. Turpin, G.C. Klein, A.G. Marshall, Atmos. Environ. 42 (2008) 1476.

[9] F. Domine, P.B. Shepson, Science 297 (2002) 1506.

[10] S. Perrier, S. Houdier, F. Domine, A. Cabanes, L. Legagneux, A.L. Sumner, P.B. Shepson, Atmos. Environ. 36 (2002) 2695.

[11] A.L. Sumner, P.B. Shepson, A.M. Grannas, J.W. Bottenheim, K.G. Anlauf, D. Worthy, W.H. Schroeder, A. Steffen, F. Domine, S. Perrier, S. Houdier, Atmos. Environ. 36 (2002) 2553

[12] C. Guimbaud, A.M. Grannas, P.B. Shepson, J.D. Fuentes, H. Boudries, J.W. Bottenheim, F. Domine, S. Houdier, S. Perrier, T.B. Biesenthal, B.G. Splawn, Atmos. Environ. 36 (2002) 2743

[13] S. Houdier, S. Perrier, F. Domine, A. Cabanes, L. Legagneux, A.M. Grannas, C. Guimbaud, P.B. Shepson, H. Boudries, J.W. Bottenheim, Atmos. Environ. 36 (2002) 2609.

[14] F. Domine, S. Houdier, A.S. Taillandier, W.R. Simpson, Atmos. Chem. Phys. 10 (2010) 919.

[15] F. Domine, L. Rey-Hanot, Geophys. Res. Lett. 29 (2002) 1873.

[16] A.M. Grannas, A.E. Jones, J. Dibb, M. Ammann, C. Anastasio, H.J. Beine, M. Bergin, J. Bottenheim, C.S. Boxe, G. Carver, G. Chen, J.H. Crawford, F. Domine, M.M. Frey, M.I. Guzman, D.E. Heard, D. Helmig, M.R. Hoffmann, R.E. Honrath, L.G. Huey, M Hutterli, H.W. Jacobi, P. Klan, B. Lefer, J. McConnell, J. Plane, R. Sander, J. Savarino, P.B. Shepson, W.R. Simpson, J.R. Sodeau, R. von Glasow, R. Weller, E.W. Wolff, T. Zhu, Atmos. Chem. Phys. 7 (2007) 4329.

[17] M. Vogel, A. Büldt, U. Karst, Fresenius J. Anal. Chem. 366 (2000) 781.

[18] S. Steinberg, I.R. Kaplan, Int. J. Environ. Anal. Chem. 18 (1984) 253.

[19] D.W. Gunz, M.R. Hoffmann, Atmos. Environ. Part A 24 (1990) 1601.

[20] R.J. Kieber, K. Mopper, Environ. Sci. Technol. 24 (1990) 1477.

[21] J.W. Munger, D.J. Jacob, B.C. Daube, L.W. Horowitz, W.C. Keene, B.G. Heikes, J. Geophys. Res. 100 (1995) 9325.

[22] K. Kawamura, S. Steinberg, I.R. Kaplan, Atmos. Environ. 30 (1996) 1035.

[23] X. Zhou, K. Mopper, Mar. Chem. 56 (1997) 201.

[24] K. Matsumoto, S. Kawai, M. Igawa, Atmos. Environ. 39 (2005) 7321

[25] K. Takeda, S. Katoh, N. Nakatani, H. Sakugawa, Anal. Sci. 22 (2006) 1509

[26] H. Wang, X. Zhang, Z. Chen, Environ. Chem. 6 (2009) 389.

[27] W. Bednarski, L. Jedrychowski, E.G. Hammond, Z.L. Nikolov, J. Dairy Sci. 72 (1989) 2474

[28] S. Hara, M. Yamaguchi, Y. Takemori, T. Yoshitake, M. Nakamura, Anal. Chim. Acta 215 (1988) 267

[29] N.R. Neng, C.A.A. Cordeiro, A.P. Freire, J.M.F. Nogueira, J. Chromatogr. A 1169 (2007) 47.

[30] L. Zardari, M. Khuhawar, A. Laghari, Chromatographia 70 (2009) 891. 
[31] K. Kawamura, Anal. Chem. 65 (1993) 3505.

[32] R. Sempére, K. Kawamura, Atmos. Environ. 28 (1994) 449.

[33] R. Sempéré, K. Kawamura, Atmos. Environ. 30 (1996) 1609.

[34] S. Matsunaga, K. Kawamura, Anal. Chem. 72 (2000) 4742.

[35] S.N. Matsunaga, A.B. Guenther, Y. Izawa, C. Wiedinmyer, J.P. Greenberg, K. Kawamura, Atmos. Environ. 41 (2007) 790.

[36] M. Igawa, J.W. Munger, M.R. Hoffmann, Environ. Sci. Technol. 23 (1989) 556.

[37] S. Houdier, M. Legrand, D. Boturyn, S. Croze, E. Defrancq, J. Lhomme, Anal. Chim. Acta 382 (1999) 253.

[38] S. Houdier, S. Perrier, E. Defrancq, M. Legrand, Anal. Chim. Acta 412 (2000) 221

[39] F. Domine, A.S. Taillandier, S. Houdier, F. Parrenin, W.R. Simpson, T.A. Douglas, in: W.F. Kuhs (Ed.), Physics and Chemistry of Ice, Royal Society of Chemistry, UK, Cambridge, 2007, p. 27.

[40] F. Domine, A.S. Taillandier, W.R. Simpson, K. Severin, Geophys. Res. Lett. 32 (2005) L13502.

[41] C. Kruisz, A. Berner, B. Brandner, in: P.M. Borrell, P. Borrell, T. Cvitas, W. Seiler (Eds.), Proceedings of the EUROTRAC Symposium '92, Academic Publishing bv The Hague, 1993 , p. 523.

[42] B. Chaloner-Gill, C.J. Cheer, J.E. Roberts, W.B. Euler, Macromolecules 23 (1990) 4597.

[43] L.A. Jones, C.K. Hancock, R.B. Seligman, J. Org. Chem. 26 (1961) 228.
[44] R.P. Gilbert, R.B. Brandt, Anal. Chem. 47 (1975) 2418

[45] G. Zurek, U. Karst, Anal. Chim. Acta 351 (1997) 247.

[46] S.D. Richardson, T.V. Caughran, T. Poiger, Y. Guo, F.G. Crumley, Ozone Sci. Eng. $22(2000) 653$.

[47] A. Lapolla, R. Flamini, T. Tonus, D. Fedele, A. Senesi, R. Reitano, E. Marotta, G. Pace, R. Seraglia, P. Traldi, Rapid Commun. Mass Spectrom. 17 (2003) 876.

[48] B.D. Pacolay, J.E. Ham, J.R. Wells, J. Chromatogr. A 1131 (2006) 275.

[49] J.R. Lakowicz, Principles of Fluorescence Spectroscopy, Springer, 2006.

[50] M. Kadirvel, A. Gbaj, D. Mansell, S.M. Miles, B. Arsic, E.V. Bichenkova, S. Freeman, Tetrahedron 64 (2008) 5598.

[51] F.W. Fitzpatrick, J.D. Gettler, J. Am. Chem. Soc. 78 (1956) 530

[52] F. Chastrette, M. Chastrette, C. Bracoud, Bull. Soc. Chim. Fr. (1986) 822.

[53] W.P. Hastings, C.A. Koehler, E.L. Bailey, D.O. De Haan, Environ. Sci. Technol. 39 (2005) 8728

[54] K.W. Loeffler, C.A. Koehler, N.M. Paul, D.O. De Haan, Environ. Sci. Technol. 40 (2006) 6318.

[55] Y.N. Lee, X. Zhou, Environ. Sci. Technol. 27 (1993) 749.

[56] X. Zhou, G. Huang, K. Civerolo, J. Schwab, Environ. Sci. Technol 43 (2009) 2753.

[57] L. Alvarez-Aviles, W.R. Simpson, T.A. Douglas, M. Sturm, D. Perovich, F. Domine, J. Geophys. Res. 113 (2008) D21304.

[58] J.S. Bowman, J.W. Deming, Geophys. Res. Lett. 37 (2010) L13501. 